\author{
Marquette University \\ e-Publications@Marquette
}

Biological Sciences Faculty Research and

Publications

Biological Sciences, Department of

3-1998

\title{
Myosin Heavy Chain Isoforms and Dynamic Contractile Properties: Skeletal Versus Smooth Muscle
}

Thomas J. Eddinger

Marquette University, thomas.eddinger@marquette.edu

Follow this and additional works at: https://epublications.marquette.edu/bio_fac

Part of the Biology Commons

\section{Recommended Citation}

Eddinger, Thomas J., "Myosin Heavy Chain Isoforms and Dynamic Contractile Properties: Skeletal Versus Smooth Muscle" (1998). Biological Sciences Faculty Research and Publications. 192.

https://epublications.marquette.edu/bio_fac/192 
Marquette University

e-Publications@Marquette

\title{
Biological Sciences Faculty Research and Publications/College of Arts and Sciences
}

This paper is NOT THE PUBLISHED VERSION; but the author's final, peer-reviewed manuscript. The published version may be accessed by following the link in the citation below.

Comparative Biochemistry and Physiology Part B : Biochemistry and Molecular Biology, Vol. 119, No. 3 (March 1998): 425-434. DOI. This article is (C) Elsevier and permission has been granted for this version to appear in e-Publications@Marquette. Elsevier does not grant permission for this article to be further copied/distributed or hosted elsewhere without the express permission from Elsevier.

\section{Myosin heavy chain isoforms and dynamic contractile properties: skeletal versus smooth muscle}

Thomas J. Eddinger

Department of Biology, Marquette University, Milwaukee, WI

\begin{abstract}
Myosin, one of the primary contractile muscle proteins, displays molecular, enzymatic, structural, functional and regulatory variability. This variability has been shown to account for a significant amount of the functional uniqueness of skeletal and smooth muscle. However, the universal generation of force and/or shortening by these two muscle types belies the ever-increasing number of known distinct differences that bring this about. Thus, the notion that the functional roles of skeletal and smooth muscle, their development and regulation, all appear to be uniquely applicable for their physiological purpose no longer appears heretical. This manuscript presents a cursory overview of the numerous ways in which these two types of muscle use a host of myosin molecules to bring about a common result, force generation and/or shortening.
\end{abstract}




\section{Keywords}

Myosin isoforms, Force production, Smooth muscle, $\mathrm{Ca}^{2+}$ sensitivity, Skeletal muscle, Fiber types, Shortening velocity, Contraction

\section{Myosin classes}

The myosin superfamily has recently been reported to be made up of at least 12 classes of myosin 9,54 , with something approaching 100 unique myosins. The commonalty generally required for a protein to be a 'myosin' includes having a similar protein structure to myosin, primarily of the head, and actin-activated $\mathrm{Mg}^{2+}$ ATPase activity. The 'gold standard' for comparison is the chicken skeletal myosin, S-1, due to its known 3-D structure [45]. Because the S1 head appears to be sufficient to perform translocation of actin and hydrolysis of ATP, this region is used to classify myosins.

The 12 potential classes of myosin currently categorized [54]show major differences while maintaining the 'core' structural organization of the molecule. Myosin II, or conventional myosin, was the first myosin known and is the most studied due to its role in muscle contraction (Fig. 1). This class is composed of two-headed proteins with long $\alpha$-helical coiled tails that form filaments. The major regions of difference for the myosin lls include the carboxyl terminal, the LMM-S2 hinge region, the $\alpha$-helix in the neck region of the S1 head and the actin and ATP loops in the S1 head. Myosin I, or unconventional myosin, is another large class of myosin which is single-headed and does not form filaments. It was first identified in Acanthamoeba [44]. These two classes of myosin show the greatest phylogenic distribution, with both being present in organisms ranging from yeast to vertebrates [54]. The remaining classes of myosin have only more recently been identified with differences which vary from these two classes from subtle to extreme. These can include the size, shape and number of S1 heads, the number and type of proteins which associate with the head, phosphorylation sites on the head or 'tail' and length and structure of the tail.

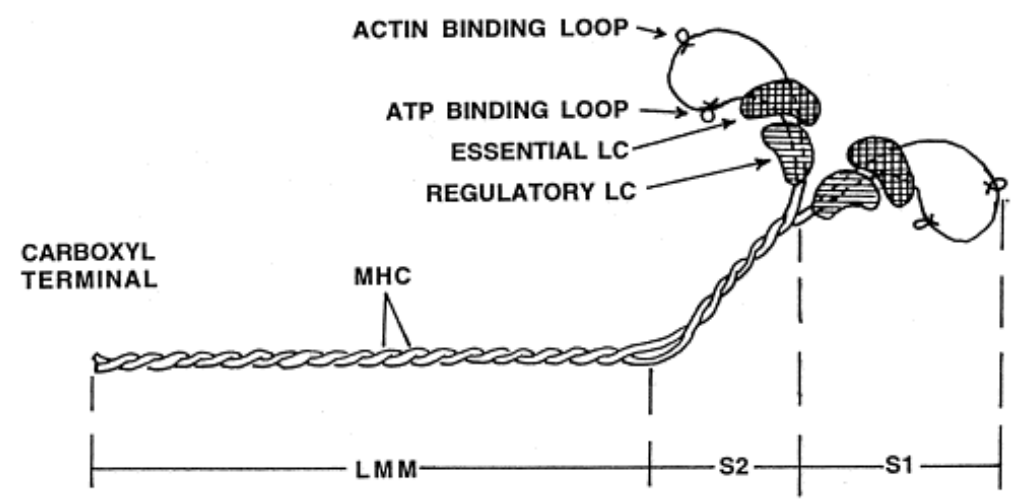

Fig. 1. Generic myosin II. The myosin is composed of two MHC and four MLC (two essential LC and two regulatory $\mathrm{LC}$ ). The MHC can be proteolytically cleaved to generate $\alpha$-helical light meromyosin (LMM), an S2 $\alpha$ helical section and the S1 globular head region. The LCs associate with the 'neck' portion of the S1 head, an $\alpha$ helical domain that connects the globular S1 amino terminal to the S2 segment.

This review will focus on the myosin heavy chain isoforms (myosin II) present in skeletal and smooth muscles. In addition, it will compare the organization and function of these two muscle types and how they may be related to these myosin isoforms. Some of these topics will only be addressed in a cursory fashion as they are the primary focus of the following articles. 


\section{Protein content and myosin isoforms}

Approximately $20 \%$ of the wet weight of skeletal muscle is protein and, of this, just over half is myofibrillar protein ( $\approx 120 \mathrm{mg} \mathrm{g}^{-1}$ muscle). Myosin makes up $\approx 45 \%$ of the myofibrillar protein ( $\approx 55 \mathrm{mg} \mathrm{g}^{-1}$ muscle), while actin makes up approximately another $20 \%\left(\approx 25 \mathrm{mg} \mathrm{g}^{-1}\right.$ muscle). In contrast, smooth muscle myosin and actin are present at $\approx 15$ and $50 \mathrm{mg} \mathrm{g}^{-1}$ muscle, respectively [40]. Thus, smooth muscle contains $\approx 1 / 3$ of the myosin and twice the actin $\mathrm{g}^{-1}$ tissue of skeletal muscle. This causes an apparent problem when one recalls that reported tension generation for both smooth and skeletal muscle is $\approx 2-3 \times 10^{5} \mathrm{~N} \mathrm{~m}^{-2}$. How does a muscle with roughly $1 / 3$ the myosin content of skeletal muscle generate the same force? Experiments looking at the duty cycle, or length of time myosin is bound to actin, may provide an answer to this question.

Protein variants with or without unique enzyme activities are referred to here as isoforms to prevent confusion of terminology. In skeletal muscle, there are at least nine myosin heavy chain (MHC) and eight myosin light chain (MLC) isoforms for which the mRNA and protein sequence is known (Fig. 2) and more which have been identified but not sequenced [51]. Extensive work has been done looking at their developmental expression, localization and potential function. In smooth muscle, much less is known about the myosin isoforms, but there appears to be no shortage of these isoforms either. Fig. 3 shows the MHC and MLC isoforms reported in smooth muscle cells.

\section{STRIATED MUSCLE MYOSIN GENES}

$\begin{array}{ll}\text { MHC } \beta / \text { Slow } & \text { MLC-1/3 Fast } \\ \text { MHC } \alpha & \text { MLC-1 Slow-a } \\ \text { MHC-2A } & \text { MLC-1 Slow/Ventricular } \\ \text { MHC-2B } & \text { MLC-1Embryonic/Atrial } \\ \text { MHC-2X } & \text { MLC-2 Fast } \\ \text { MHC-Embryonic } & \text { MLC-2 Slow/Ventricular } \\ \text { MHC-Neonatal } & \text { MLC-2 Mandibular } \\ \text { MHC-Extraocular } & \text { MLC-2 Atrial }\end{array}$

MHC-Mandibular

Fig. 2. List of skeletal MHC and MLC isoforms for which the mRNA and protein sequences are known (modified from [51]). 


\section{SMOOTH MUSCLE MYOSIN PROTEINS}

$\begin{array}{ll}\text { SM1 } & \text { SM LC }_{20} \\ \text { SM2 } & \mathrm{NMLC}_{20} \\ \mathrm{SM}_{\mathrm{i}} & \mathrm{LC}_{17 \mathrm{a}} \\ \mathrm{SM}_{\mathrm{i}} & \mathrm{LC}_{17 \mathrm{~b}} \\ \mathrm{NM}_{\mathrm{A}} & \\ \mathrm{NM}_{\mathrm{B}} & \\ \mathrm{NM}_{\text {emb }} & \end{array}$

Fig. 3. List of smooth muscle MHC and MLC isoforms for which the mRNA and protein sequences are known. There is one gene for all the SM MHC isoforms and one gene for both of the MLC 17 isoforms. The NM MHC isoforms and the $\mathrm{LC}_{20}$ isoforms are each from different genes. SM1 and SM2 refer to the carboxyl terminal SM isoforms, while $\mathrm{SM}_{i}$ and $\mathrm{SM} 2_{i}$ refer to the presence of the amino terminal insert $\mathrm{SM}$ isoforms.

In general, there is a great deal more known about the skeletal muscle myosin isoforms and their functional significance than there is for smooth muscle. It does not make sense teleologically to have all these different isoforms if they do not perform unique functions, but as of the present there is a dearth of evidence for functional correlations for the myosin isoforms in smooth muscle. With the application of new experimental techniques, possible functional significance may be resolved in the near future.

\section{Muscle organizational differences}

Skeletal muscle has a very well defined anatomical organization. A muscle is composed of single muscle cells, or fibers which are surrounded by a connective tissue sheath, the endomysium. These individual cells are grouped together by a second connective tissue layer, the perimysium, to form fascicles or bundles of fibers. Finally, all the fascicles are grouped together to form the muscle and surrounded by a dense connective tissue layer, the epimysium. These fibers can run from one end of the muscle to the other or may extend only a portion of the length of the muscle. In most skeletal muscles, the fibers run from the tendinous insertion to the tendinous origin of the muscle. These tendons can extend over a significant portion of the muscle, such that it is not common for individual fiber lengths to be as long as the total muscle length. In smooth muscle, the muscle cells are not as clearly segmented into smaller groups in this fashion. Most smooth muscles form hollow structures, with the inner layer generally being of epithelial origin. The smooth muscle cells may all have a similar orientation (some blood vessels), or have multiple orientations in layers (i.e. intestine, bladder). The outermost layer is connective tissue of varying complexity and organization, depending on the muscle.

At the cellular level, striated muscle fibers are much larger than SMCs (mm vs. $\mu \mathrm{m}$ in length; $10-100 \mu \mathrm{m}$ vs. 1$10 \mu \mathrm{m}$ in diameter). Skeletal muscle cells are multinucleate with the nuclei located around the cell's periphery just under the sarcolemma. SMCs have a single centrally located nucleus that is often spindle-shaped. It is not uncommon to find smooth muscle cells which have multiple ends or are extensively branched ([21], personal observation). Skeletal muscle fibers have a highly repetitive filament organization which appears as a striation pattern in longitudinal section while SMCs do not. The exact organization of filaments in SMCs is not known. Skeletal muscles also have an extensive T-tubule and sarcoplasmic reticular (SR) system, while there is no Ttubule system and limited SR in smooth muscle. In skeletal muscle, there is innervation of every fiber, which is not the case for many smooth muscle tissues. 
Within both skeletal and smooth muscle cells, thick (primarily myosin) and thin (primarily actin) filaments are believed to interdigitate to allow tension generation and/or shortening. The gross organization of the thick filaments is believed to be very different between these two muscle types. In skeletal muscle, the thick filaments are believed to be 'bipolar' (Fig. 4A) with the myosin heads of each half sarcomere pointing out towards their Z lines. There is a central bare zone where there are no myosin heads. In smooth muscle, the thick filament is believed to be 'side polar' (Fig. 4B) with all the myosins on one side of the filament facing in one direction and all the myosins on the opposite side, facing in the opposite direction 12, 71. There is no central bare zone in the side polar filament. This unique filament organization, along with the lack of sarcomeres in SMCs, may in part account for the cells ability to shorten to a much greater extent than skeletal fibers. In addition, in isolated SMCs shortening has been reported to occur in a cork screw-like fashion, which may be due to contractile filament and/or cytoskeletal organization and may also explain some of the differences between these muscle systems [68].

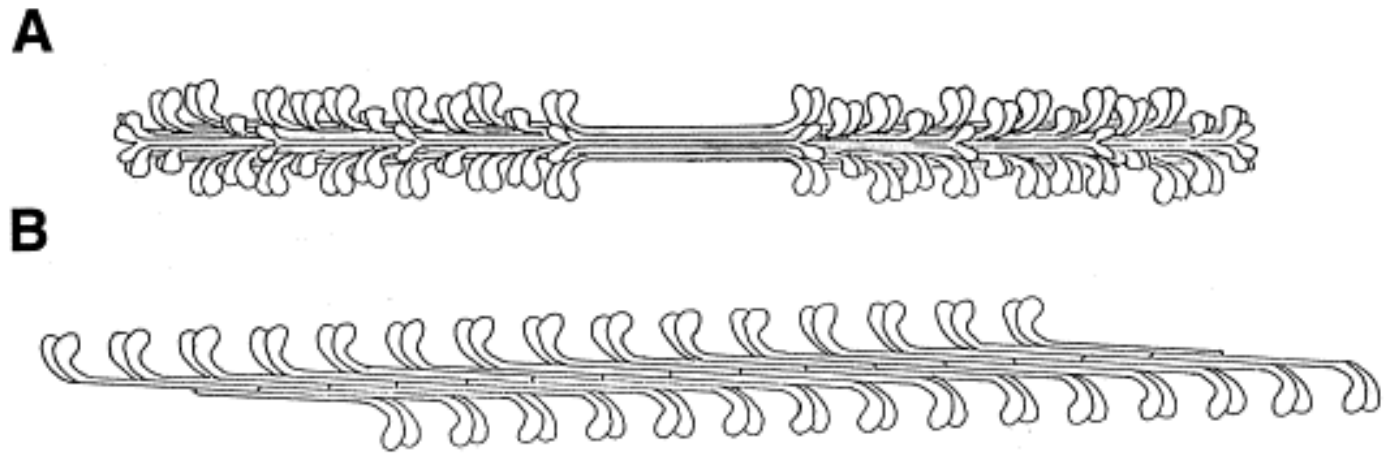

Fig. 4. Models of myosin arrangement in: (A) Skeletal muscle-the myosin molecules form a 'bipolar filament' with S1 heads facing away from the center of the filament to give the filament symmetry around a transverse axis through the middle of the filament. (B) Smooth muscle - the myosin molecules form a 'side-polar filament' with $\mathrm{S} 1$ heads facing in the same direction on each side of the molecule.

\section{Activation}

The primary mechanism of activation for skeletal muscle is via innervation. In SMCs, neurotransmitters also play a role, but hormones, ions, metabolites and other receptor agonists may play a more significant role 31, 59, 67. Activation in skeletal muscle causes release of $\mathrm{Ca}^{2+}$ from internal SR stores. In smooth muscle, while this mechanism also exists, the SMCs are critically dependent on external $\mathrm{Ca}^{2+}$ stores. SMCs can neither generate repetitive contractions nor maintain tonic contractions without external $\mathrm{Ca}^{2+}$. In skeletal muscle the primary regulation of the contraction results from this intracellular $\mathrm{Ca}^{2+}$ binding to troponin $\mathrm{C}$ (TNC). Because TNC is a thin filament bound protein, this is often referred to as thin filament regulation. In smooth muscle, there is no TNC. The primary method for contractile regulation is for the intracellular $\mathrm{Ca}^{2+}$ to phosphorylate myosin light chain $20\left(\mathrm{MLC}_{20}\right)$ by a calmodulin-kinase mechanism [25]. This is often referred to as thick filament regulation. The net effect for both muscles is tension generation and/or shortening. Thus, while both muscle types can produce tension and/or shortening, if one looks beyond the cursory they find innumerable differences in how this is accomplished. This brief summary cannot cover all the significant details and overlooks other possible mechanisms which suggest thick filament regulatory mechanisms in skeletal muscle (i.e. myosin phosphorylation) and possible thin filament regulatory mechanisms (i.e. calponin/caldesmin) in smooth muscle $19,33,57,65,66$. The role of these and other regulatory mechanisms is not as well understood, but will undoubtedly add to the complexity and diversity of each of these muscle systems. 


\section{5. $\mathrm{Ca}^{2+}$ sensitivity}

There are four major fiber types in skeletal muscle (I, Ila, IIx and IIb) in animals that express primarily these four MHC isoforms 13,49 . In humans, only three major MHCs have been identified in skeletal muscle (I, Ila, IIb). The human type IIb gene is very homologous with the rat type IIx gene and there is no isoform homologous to the rat IIb MHC in humans 17, 56. Thus, the nomenclature is confusing on this issue with some authors using the traditional IIb nomenclature in humans 4, 30and others using the Ilx nomenclature [69]. These fiber types show a differential sensitivity to $\mathrm{Ca}^{2+}$ concentration (I>lib>lla) [51], which is especially apparent at submaximal $\mathrm{Ca}^{2+}[7]$. The tension-pCa curves show a sigmoidal relationship with the type I fibers showing a shallower curve and the fast type II fibers showing a much steeper relationship. Other proteins undoubtedly play a role in this difference, but skeletal fibers are generally classified by their myosin content. In smooth muscle there is also a sigmoidal relationship between $\mathrm{Ca}^{2+}$ and tension, but the curve is shifted to the left relative to skeletal muscle, i.e. SMCs are more sensitive to $\mathrm{Ca}^{2+}$ than skeletal fibers [39]. In skeletal muscle, the $\mathrm{Ca}^{2+}$-tension relationship can be shifted to the left (increased sensitivity) by phosphorylation of the myosin light chain [62]. In smooth muscle, the $\mathrm{Ca}^{2+}$-tension relationship is also affected by the amount of $\mathrm{MLC}_{20}$ phosphorylation. This may be a more significant factor in smooth muscle where different agonists work on different $\mathrm{Ca}^{2+}$-phosphorylation relationships ([59]). As mentioned above, multiple activation mechanisms are involved in smooth muscle activation.

\section{Shortening velocity}

In 1967, Bárány [1]reported that the ATPase of myosin correlated with muscle shortening speed for the 14 muscles examined. Since then, numerous investigators using various methods, have shown that fibers expressing different myosin isoforms have distinct shortening velocities. Skeletal type I fibers are slower than type Ila, which are slower than type IIb ([51]). Velocity for these three skeletal fiber types range from $\approx 0.5-5.0$ muscle lengths s$~^{-1}\left(\mathrm{ML} \mathrm{s}^{-1}\right)$ at $15^{\circ} \mathrm{C}$, with a $Q_{10}$ of $\approx 2.0$. More recent studies of $\mathrm{MHC}$ composition in skeletal fibers have used immunological and molecular techniques in addition to histochemical and electrophoretic analyses. Numerous reports in the literature suggest, that in addition to the four major skeletal fiber types, there is a continuum of fibers expressing a mixture of the four skeletal $\mathrm{MHC}$ molecules [52]. Single skinned skeletal fiber experiments suggest that the type and/or mixture of the $\mathrm{MHC}$ isoforms present in a fiber determine its $\mathrm{M}$ ATPase activity [5]mechanical $V_{\max }$ [30] and contractile properties $\left(P_{0}, V_{0} ; 23,69\right)$. In contrast, there are also reports that variability in maximal shortening velocity of fast fibers can not be explained by MHC coexistence in fibers [2]. Complicating factors, including the role of the various MLC and other contractile and regulatory protein isoforms, confound these studies as there are reports that these (MLC's) can modulate shortening velocity 3,6 .

In contrast to skeletal muscle, smooth muscle has a velocity of $\approx 0.01-0.30 \mathrm{ML} \mathrm{s}^{-1}$, depending on phosphorylation levels, or roughly $50-100$ times slower than skeletal muscle. Extrapolation to $37^{\circ} \mathrm{C}$ and full phosphorylation would give a shortening of velocity range closer to that of skeletal muscle, but still slower by roughly an order of magnitude. This suggests that there are other factors that are significant in the intact smooth muscle system [42].

Estimates of maximal shortening velocity may also be obtained from force-velocity curves. Under maximal activation, there is a single inverse concave relationship between force and velocity for a skeletal fiber (Fig. 5). However, this is not the case in smooth muscle. Myosin phosphorylation is a transient event in smooth muscle. Unlike skeletal muscle, where there is an all-or-none activation of the fiber, smooth muscle can be activated to variable extent depending on the method and duration of activation (see above). Thus, it is rare, if ever, that there is full phosphorylation of myosin in SMCs. In addition, the level of phosphorylation changes with time following activation. Because myosin phosphorylation is believed to be required to activate smooth muscle and 
is correlated with velocity, the maximum velocity varies with phosphorylation levels. Thus, there is a unique force-velocity curve and thus maximal shortening velocity for each phosphorylation level (Fig. 5B).

Phosphorylation levels change with $\mathrm{Ca}^{2+}$ and thus, do not remain constant during activation. Thus, shortening velocity increases immediately following activation until it reaches a peak and then decreases as $\mathrm{Ca}^{2+}$ decreases with time following the start of activation [38].

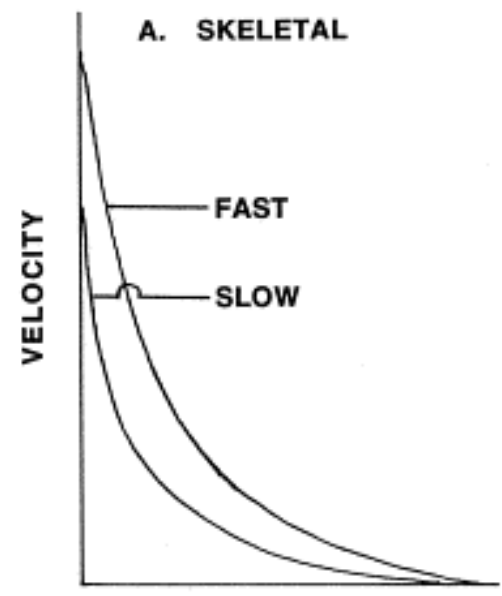

FORCE
B. SMOOTH

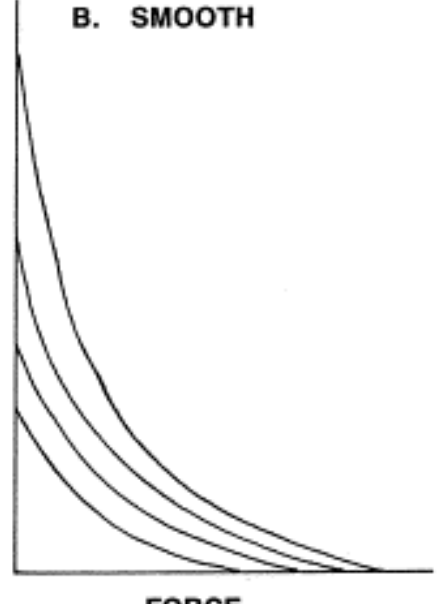

FORCE

Fig. 5. Graphs of the force-velocity relationship observed in skeletal and smooth muscles. (A) Skeletal musclethe two major types of skeletal fibers are readily separated by these measurements with full activation. Each fiber type gives a unique relationship. (B) Smooth muscle-in smooth muscle, the type of activation used can lead to different myosin phosphorylation levels which will give a whole series of $\mathrm{F}-\mathrm{V}$ relationship rather than one unique relationship. (There would be a continuum of these curves; only four are shown for clarity.)

Investigators have also used the motility assay to measure myosin function. This method allows one to use purified myosin or myosin fragments and control all the known conditions involved in the contraction reaction. Sellers et al. [53] have reported that the actin sliding speed $\left(\mu \mathrm{m} \mathrm{s}^{-1}, 25^{\circ} \mathrm{C}\right)$ is 0.04 for chicken brush border myosin I and human platelet myosin II. Turkey gizzard smooth muscle myosin moves actin approximately one order to magnitude fast $\left(0.2 \mu \mathrm{m} \mathrm{s}^{-1}\right)$. Rabbit slow and fast muscle myosin moved actin even faster $\left(0.8\right.$ and $\left.4.5 \mu \mathrm{m} \mathrm{s}^{-1}\right)$. The quantitative differences among these myosins appear to be the same regardless of whether the experiments are done in permeabilized fibers or on purified proteins. The range of values reported for different intact smooth muscles is much greater however, than for that reported on purified proteins.

There are some significant differences between skeletal and smooth muscle which make these types of comparisons suspect. As discussed by Murphy et al. [42], there are additional factors which make maximum velocity measurements particularly difficult. Filament lengths, cellular organization, the broad length-tension relationship (Section 7), load and phosphorylation levels all affect shortening velocity. Differences in any of these (and often none of them are controlled for) can alter shortening measurements.

There are reports in the literature suggesting correlations between the SM myosin isoforms and function. Sparrow et al. 27, 60have published small positive correlations between SM1 MHC (tail isoform) content and $V_{\max }$ in rat myometrial tissue. In conflict with these reports, Cai et al. [8] have recently reported that a 13 amino acid peptide matching part of the unique SM1 tail decreases contraction velocity in permeabilized SM. They suggest that the nonhelical tail portion of the SM MHC may modulate contractility and possibly the latch state during shortening with increased SM1 MHC isoform content. In addition, Kelley et al. [28]reported no difference in an in vitro motility assay of purified SM1 and SM2 homodimeric myosin molecules. However, if there is an intermolecular interaction between neighboring molecules, this method would not detect it. 
There are also reports that the ratio of the myosin light chain $17\left(\mathrm{MLC}_{17}\right)$ isoforms correlates with shortening velocity. An increased relative amount of $\mathrm{MLC}_{17 \mathrm{a}}$ has been reported to correlate with increased ATPase activity [26]and $V_{\max }$ [36]. Malmqvist and Arner [32]reported a 7-fold difference in $V_{\max }$ values from five different smooth muscle tissues, which correlated with $\mathrm{MLC}_{17}$ isoforms. They did not measure $\mathrm{MHC}$ isoforms in this study to see if they had any effect. In contrast to these reports however, Kelley et al. [29]showed that changing the relative amount of $\mathrm{LC}_{17 \mathrm{a}}$ on $\mathrm{SM}$ myosin does not alter in vitro motility rates. They did report, however, that the presence of the insert in the head region of the SM MHC does correlate with in vitro motility, actin movement velocities and $\mathrm{Mg}^{2+}$-ATPase activity [29]. More recently, Rovner et al. [46] expressed homogeneous populations of SM heavy meromyosin (HMM) with and without the 7AA head insert. They reported a 2-fold higher enzymatic activity and in vitro motility for the HMM with the 7AA head insert. They also found no effect of the $\mathrm{MLC}_{17}$ isoforms on velocity. Sata et al. [48]generated chimeric myosin made of the skeletal muscle MHC globular head and smooth muscle C-terminal S1 head and S2 region and light chains. Their results suggest the C-terminal S1 head region confers regulation by LC phosphorylation, while the motor domain regulates the rate of ATP hydrolysis.

\section{Length-tension relationship}

The length-tension relationship for skeletal vs. smooth muscle show some distinct differences which are shown schematically in Fig. 6. The first major difference entails the passive tension relationship. In skeletal muscle, there is very little passive tension at $L_{o}$ (optimal muscle length for tension production), while in smooth muscle there is a significant passive tension component at $L_{0}$. This is most likely due to the extensive extracellular connective tissue present in smooth muscle tissues. This difference also causes a major difference between the skeletal and smooth muscle total tension curves. In skeletal muscle, total tension increases with increasing fiber length to a maximum at $L_{0}$. At longer lengths, total tension decreases and peak tension is not exceeded until non-physiological lengths when the passive tension becomes extremely large. In smooth muscle, the total tension curve shows a continuous increase with increasing fiber length. This may be important as it is more probable that these cells may reach these long lengths than it is for skeletal muscle fibres. A second major difference, that has been exaggerated in the figure for clarity, is the peak of the active curve (Fig. 6). Relative to skeletal muscle, the smooth muscle active tension curve has a very broad flat peak 14,70 . This may in part, also be due to the extensive connective tissue present in smooth muscle tissue. The normal physiological situation is, of course, with the cells in a tissue with the surrounding connective tissue. This broad peak allows smooth muscle to generate near maximal force over a greater range of lengths than skeletal muscle. This may again be important as smooth muscle cell length may function over a broader range of lengths in physiological conditions than skeletal muscle [70]. There is also evidence that there is a mechanism in smooth muscle which allows an adjustment of the force generating capacity of a muscle by adjusting intracellular filament organization during contraction [22]. 


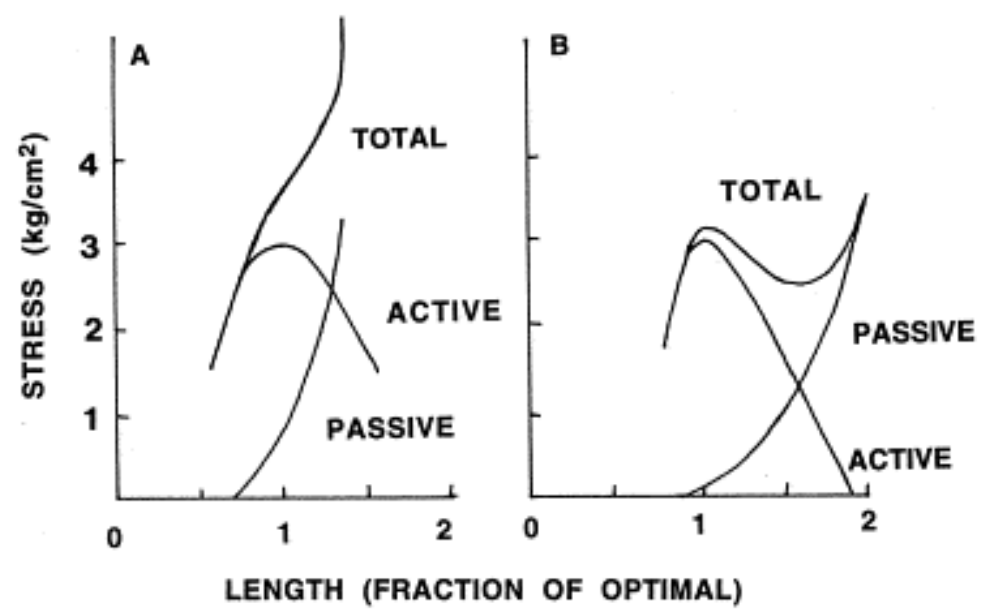

Fig. 6. Schematic graphs of the length-tension relationship in smooth (A) and skeletal (B) muscle. While gross appearances are similar, three distinct differences are noted. (1) The active tension curve for smooth muscle has a distinctly broader 'peak' and shows active force to shorter lengths than the skeletal muscle. (2) The passive tension curve in smooth muscle begins at shorter lengths and generates significantly more tension than skeletal muscle at comparable lengths. (3) The total tension curve in smooth muscle shows a continuously increasing slope, while in skeletal muscle there is a decrease in total tension between $\approx 1.0$ and $1.5 L_{o}$ (modified from [38]).

There is some work that has been done on the single SMC level examining the L-T relationship. Unlike skeletal muscle, smooth muscle requires rather harsh enzymatic digestions to isolate the single SMCs. There are, however, a number of investigators that have been able to get viable isolated SMCs for mechanical measurements. Harris and Warshaw [24] have reported measurements on the ascending limb of the L-T curve from isolated SMCs. By making a series of force measurements at various cell lengths, they were able to obtain a linear relationship from $\approx 0.6-1.0$ optimal cell length, which extrapolated to zero force at 0.4 optimal cell length. When the cell was stretched to lengths from 1.0 to 1.4 optimal cell length, no plateau or descending limb was observed, but rather a shifting of the L-T curve along the length axis without changing its shape. A possible explanation is that there is an adjustment of the filament organization and/or the cytoskeleton, depending on the initial length of the cell prior to contraction [22]. Limitations of the experimental design due to a single possible activation of each single cell precludes a definitive explanation for these results. Further work is needed in this area.

\section{Force production}

Values for tension generation in both smooth and skeletal muscle fall in the range of $1-3 \times 10^{5} \mathrm{~N}$ $\mathrm{m}^{-2} 10,37,41,42$. Thus, smooth muscle generates similar tensions to skeletal muscle with $1 / 3$ to $1 / 5$ of the myosin content. In addition, smooth muscle is much more economical in doing this. Estimates of skeletal and smooth muscle efficiency (mechanical work/ATP consumed) show smooth muscle to be only $1 / 4$ as efficient as skeletal muscle. In contrast, however, smooth muscle is estimated to be over 300 times as economical (stress maintenance/ATP consumed) [38]. This is significant as most smooth muscles do little 'work' (forcexdistance) as they maintain tonic conditions at a fixed length over extended periods of time. Skeletal muscles, on the other hand, do a great deal of 'work' relative to tonic contractions.

While force production appears to be an easy measurement, there are many considerations that must be taken into account. Correct values require that maximum force $\left(\mathrm{N} \mathrm{m}^{-2}\right)$ is generated, the measurements are made in the correct force axis, and that extracellular space is accounted for as well as filament length and packing $41,42$. Investigators have also looked at force production in single cell preparations. In striated muscle, the four major fiber types with unique myosin heavy chain isoforms also show specific forces in the same range as reported for 
whole muscle experiments [23]. Some investigators have reported significantly different force production for the different fiber types, while others observe similar specific forces for the different specific fiber types $16,63$. In smooth muscle, there are no reports of force production being correlated with smooth muscle myosin isoforms. This could be because there is no difference, or it could be because of technical limitations in trying to do these experiments.

There are significant concerns over these single SM cell studies. Isolation of single SM cells requires fairly harsh enzymatic conditions. In addition, cell isolation would disrupt any intercellular associations which would include mechanical linkages. This could affect intracellular filament organization and thus force generation. Currently, there are no data concerning this issue. Force production is also dependent on the length of the cell, the amount of phosphorylation and the number of contractile filaments present in the cells. Thus, while single SMC forces in the range of $1 \mu \mathrm{N}$ have been reported, it is difficult to relate this to the whole tissue. All of these issues need to be addressed in order for a valid comparison of force between cells and/or tissues from different muscles to be made. Experiments performed on myosin molecules avoid some of these issues, but sidestep the fact that in vivo, myosin II only produces force when it is part of a filament and thus the structure, organization and number of filaments needs to be addressed.

\section{Fiber type distribution}

In skeletal muscle, fiber types have been identified by genetic, physiological, anatomical and biochemical criteria. The simplest division is into two categories, generally referred to as slow and fast fibers (or type I and type II). Often the fast fibers are further divided to type Ila, IIx and IIb. At a simplistic level, each of these fiber types has a unique myosin isoform content. Thus, a type I fiber has type I myosin and a type II fiber has type II myosin (Ila, IIx, Ilb). Unfortunately, reality is not this simple, and many fibers have been observed expressing multiple myosin isoforms [51]. While it is clear that single fibers can be found containing multiple myosin isoforms, it may not be clear if this is a rule or an exception. Skeletal muscle is a 'plastic' tissue which can adapt to the demands placed on it. Developmentally, a given skeletal muscle needs to adapt to its physiological situation and skeletal muscles often show fibers with multiple myosin isoforms (in addition to other protein isoform shifts). In addition, various perturbations made on mature skeletal muscle (electrical stimulation, hormonal changes, physical training and/or inactivation) have all been reported to change myosin isoform composition in skeletal muscles and can result in fibers expressing multiple myosin

isoforms 7, 11, 43, 47, 50, 64, 61, 69. Fibers with multiple isoforms can also be observed in 'normal' adult muscle however. Thus, either muscle fibers can normally express multiple myosin isoform or they are always in a state of transition around some equilibrium point. While fibers expressing multiple myosin isoforms may not be the rule, it is definitely not the exception.

In smooth muscle, evidence for cellular heterogeneity and 'cell types' has only more recently begun to emerge. With the knowledge of the many smooth and nonmuscle myosin isoforms that can exist in smooth muscle tissues, evidence has also been obtained suggesting SM cellular heterogeneity [58]. Small et al. [55]described two domains in smooth muscle cells (a contractile domain including myosin and caldesmin and a cytoskeletal domain including filamin and desmin) based on immunohistochemistry. Giurato et al. [20]reported unique distributions for the NM myosin isoforms in cultured aorta SM cells. Immunohistochemical studies on tissue sections 18,72 , 73show populations of cells with unique protein composition that are regionally localized from lumen to adventitia of the vessel.

We have reported intercellular variability between SM cells from vascular arteries [35]. Reverse transcriptionpolymerase chain reaction (RT-PCR) was used to amplify the mRNA for the SM1 and SM2 MHC isoforms from enzymatically dispersed single SM cells. Carotid tissue samples from five rabbits had a mean SM2/SM1 ratio of $0.49 \pm 0.05$, while 59 isolated cells from six rabbit carotids had a mean SM2/SM1 ratio of $0.44 \pm 0.29$. The range of 
values for the SM2/SM1 ratio from the multicellular tissue samples was from 0.43 to 0.56 , while this same range from the single cells extended from 0 to 1.8 [35]. These results indicate there is a greater range of variability in the amount of the two SM MHCs expressed in single SM cells from a given vessel than between animals. These data also suggest that there is cellular heterogeneity in smooth muscles. How this compares to skeletal muscle is not currently known.

The arrangement of these different cells in vascular tissue is also unknown. There are numerous possible distributions for these cells. These could include a heterogeneous mosaic pattern similar to that observed in skeletal muscle or random pockets of cells. The cells could also be arranged in some type of gradient fashion from lumen to adventia [15], which would be consistent with reports of immunohistochemical studies (see above). The arrangement of these heterogeneous cells in the vessel may be important for cellular regulation and function. This requires further work before hypotheses can be designed and tested.

We have begun a series of experiments to test for possible correlations between mechanical properties and SM MHC isoforms. Single isolated vascular SMCs are used to measure maximum unloaded shortening velocity and subsequently used for molecular analysis of their SM MHC protein composition. The single SMCs are permeabilized with $\alpha$-toxin and activated with a cocktail of $\mu \mathrm{M}$ histamine, phenylephrine and $\mathrm{Ca}^{2+}$. For the 28 cells examined using these procedures, there was no significant correlation between the SM2/SM1 MHC isoform ratio and the maximum unloaded shortening velocity of these cells [34]. There is a significant correlation between increasing SM1 relative content and the final length to which the cell can shorten. Further studies examining for possible correlations with these isoforms and force production, the MHC head isoforms, maximum force, and shortening velocity will determine if these variables are correlated.

Skeletal and smooth muscle appear to be as dissimilar as two muscle types can be. However, there are still numerous similarities. While the details have little in common, the overall picture is the same. Contractile proteins are regulated to generate force and/or cause cell shortening. New methods and interdisciplinary approaches have and will continue to advance our understanding of these two amazing muscle tissues. In the final analysis, it is the differences between these muscles that makes them unique and these differences need to be understood to interpret how each of these muscle types meets the unique functional demands placed on it by the organism.

\section{References}

1 M. Bárány. ATPase activity of myosin correlated with speed of muscle shortening. J Gen Physiol, 50 (1967), pp. $197-218$

2 R. Bottinelli, R. Betto, S. Schiaffino, C. Reggiani. Maximum shortening velocity and coexistence of myosin heavy chain isoforms in single skinned fast fibres of rat skeletal muscle. J Muscle Res Cell Motil, 15 (1994), pp. 413-419

3 R. Bottinelli, R. Betto, S. Schiaffino, C. Reggiani. Unloaded shortening velocity and myosin heavy chain and alkali light chain isoform composition in rat skeletal muscle fibres. J Physiol, 478 (1994), pp. 341-349

4 R. Bottinelli, M. Canepari, M.A. Pellegrino, C. Reggiani. Force-velocity properties of human skeletal muscle fibres: Myosin heavy chain isoform and temperature dependence. J Physiol, 495 (1996), pp. 573-586

5 R. Bottinelli, M. Canepari, C. Reggiani, G.J.M. Stienen. Myofibrillar ATPase activity during isometric contraction and isomyosin composition in rat single skinned muscle fibres. J Physiol, 481 (1994), pp. 663-675

6 R. Bottinelli, C. Reggiani. Force-velocity properties and myosin light chain isoform composition of an identified type of skinned fibres from rat skeletal muscle. Pflüg Arch, 429 (1995), pp. 592-594

7 A.J. Buller, J.C. Eccles, R.M. Eccles. Interactions between motorneurons and muscles in respect to the characteristic speeds of their responses J Physiol, 150 (1960), pp. 417-439 
8 J. Cai, D.G. Ferguson, A.F. Martin, R.J. Paul. Smooth muscle contractility is modulated by myosin tail-S2-LMM hinge region interaction. Am J Physiol, 269 (1995), pp. 1126-1132

9 R.E. Cheney, M.A. Riley, M.S. Mooseker. Phylogenetic analysis of the myosin superfamily. Cell Motil Cytoskel, 24 (1993), pp. 215-223

10 R.I. Close. Dynamic properties of mammalian skeletal muscle. Physiol Rev, 52 (1972), pp. 129-197

11 R.I. Close, M. Bárány. The transformation of myosin in cross-innervated muscles. J Physiol Lond, 213 (1971), pp. $455-474$

12 P.H. Cooke, F.S. Fay, R. Craig. Myosin filaments isolated from skinned amphibian smooth muscle cells are side-polar. J Muscle Res Cell Motil, 10 (1989), pp. 206-220

13 C. De Nardi, S. Ausoni, P. Moretti, L. Gorza, M. Velleca, M. Buckingham, S. Schiaffino. Type 2X myosin heavy chain is coded by a muscle fiber type-specific and developmentally regulated gene. J Cell Biol, 123 (1993), pp. 823-835

14 S.P. Driska, D.N. Damon, R.A. Murphy. Estimates of cellular mechanics in an arterial smooth muscle. Biophys J, 24 (1978), pp. 525-540

15 TJ Eddinger, DP Meer. Smooth muscle heterogeneity: Does the striated muscle model apply? Can J Physiol Pharmacol, 75 (1997), pp. 861-868

16 T.J. Eddinger, R.L. Moss. Mechanical properties of skinned single fibers of identified types from rat diaphragm. Am J Physiol (Cell Physiol), 253 (22) (1987), pp. 210-218

17 S. Ennion, J.S.A. Pereira, A.J. Sargeant, A. Young, G. Goldspink. Characterization of human skeletal muscle fibres according to the myosin heavy chains they express. J Muscle Res Cell Motil, 16 (1995), pp. 35-43

18 M.G. Frid, E.P. Moiseeva, K.R. Stenmark. Multiple phenotypically distinct smooth muscle cell populations exist in the adult and developing bovine pulmonary arterial media in vivo. Circ Res, 75 (1994), pp. 669681

19 M. Gimona, J. Small, V. Calponin M. Bárány (Ed.), Biochemistry of Smooth Muscle Contraction, Academic Press, San Diego (1996), pp. 91-103

20 L. Giurato, M. Scatena, A. Chiavegato, M. Tonello, G. Scannapieco, P. Pauletto, S. Sartore. Non-muscle myosin isoforms and cell heterogeneity in developing rabbit vascular smooth muscle. J Cell Sci, 101 (1992), pp. 233-246

21 R.P. Gould. The microanatomy of muscle. G.H. Bourne (Ed.), The Structure and Function of Muscle, Academic Press, Location (1973), pp. 186-241

22 S.J. Gunst, R.A. Meiss, M-F. Wu, M. Rowe. Mechanisms for the mechanical plasticity of tracheal smooth muscle. Am J Physiol (Cell Physiol), 268 (37) (1995), pp. 1267-1276

23 S.D.R. Harridge, R. Bottinelli, M. Canepari, M.A. Pellegrino, C. Reggiani, M. Esbjörnsson, B. Saltin. Wholemuscle and single-fibre contractile properties and myosin heavy chain isoforms in humans. Pflüg Arch, 432 (1996), pp. 913-920

24 D.E. Harris, D.M. Warshaw. Length vs. active force relationship in single isolated smooth muscle cells. Am J Physiol (Cell Physiol), 260 (29) (1991), pp. C1104-C1112

25 D.J. Hartshorne. Biochemistry of the contractile process in smooth muscle. L.R. Johnson (Ed.), Physiology of the Gastrointestinal Tract, Raven Press, New York (1987), pp. 423-482

26 Y. Hasegawa, F. Morita. Role of 17 kDa essential light chain isoforms of aorta smooth muscle myosin. J Biochem, 111 (1992), pp. 804-809

27 T.E. Hewett, A.F. Martin, R.J. Paul. Correlations between myosin heavy chain isoforms and mechanical parameters in rat myometrium. J Physiol, 460 (1993), pp. 351-364

28 C.A. Kelley, J.R. Sellers, P.K. Goldsmith, R.S. Adelstein. Smooth muscle myosin is composed of homodimeric heavy chains. J Biol Chem, 267 (1992), pp. 2127-2130 
29 C.A. Kelley, M. Takahashi, J.H. Yu, R.S. Adelstein. An insert of seven amino acids confers functional differences between smooth muscle myosin from the intestines and vasculature. J Biol Chem, 268 (1993), pp. 12848-12854

30 L. Larsson, R.L. Moss. Maximum velocity of shortening in relation to myosin isoform composition in single fibres from human skeletal muscles. J Physiol, 472 (1993), pp. 595-614

31 M.R. Lee, L. Li, T. Kitazawa. Cyclic GMP causes $\mathrm{Ca}^{2+}$ desensitization in vascular smooth muscle by activating the myosin light chain phosphatase. J Biol Chem, 272 (1997), pp. 5063-5068

$32 \mathrm{U}$. Malmqvist, A. Arner. Correlation between isoform composition of the $\mathbf{1 7} \mathrm{kDa}$ myosin light chain and maximal shortening velocity in smooth muscle. Pflüg Arch, 418 (1991), pp. 523-530

33 SB Marston, PA Huber. Caldesmon. M. Bárány (Ed.), Biochemistry of Smooth Muscle Contraction, Academic Press, San Diego (1996), pp. 77-90

34 DP Meer, TJ Eddinger. Expression of smooth muscle myosin heavy chains and unloaded shortening in single smooth muscle cells. Am J Physiol (Cell Physiol), 273 (42) (1997), pp. C1259-1266

35 D.P. Meer, T.J. Eddinger. Heterogeneity of smooth muscle myosin heavy chain expression at the single cell level. Am J Physiol (Cell Physiol 39), 270 (1996), pp. 1819-1824

36 I. Morano, G. Erb, B. Sogi. Expression of myosin heavy and light chains changes during pregnancy in the rat uterus. Pflüg Arch, 423 (1993), pp. 434-441

37 R.A. Murphy. Contraction of muscle cells. R.M. Berne, M.N. Levy (Eds.), Physiology, Mosby, St. Louis (1988), p. 323

38 R.A. Murphy. Muscle cells of hollow organs. News Physiol Sci, 3 (1988), pp. 124-128

39 R.A. Murphy. What is special about smooth muscle? The significance of covalent crossbridge regulation? FASEB J, 8 (1994), pp. 311-318

40 R.A. Murphy, S.P. Driska, D.M. Cohen. Variations in actin to myosin ratios and cellular force generation in vertebrate smooth muscles. R. Casteels, et al. (Eds.), Excitation-Contraction Coupling in Smooth Muscle, Elsevier/North Holland Biomedical Press, New York (1977), pp. 417-424

41 R.A. Murphy, J.T. Herlihy, J. Megerman. Force-generating capacity and contractile protein content of arterial smooth muscle. J Gen Physiol, 64 (1974), pp. 691-705

42 R.A. Murphy, J.S. Walker, J.D. Strauss. Myosin isoform and function diversity in vertebrate smooth muscle. Comp Biochem Physiol, 117 (1997), pp. 51-60

43 L. Nwoye, W.F.H.M. Mommaerts, D.R. Simpson, K. Seraydarian, M. Marusich. Evidence for a direct action of thyroid hormone in specifying muscle properties. Am J Physiol (Regul Integr Comp Physiol), 242 (11) (1982), pp. 401-408

44 T.D. Pollard, E.D. Korn. Acanthamoeba myosin. I. Isolation from Acanthamoeba castellanii of an enzyme similar to muscle myosin. J Biol Chem, 248 (1993), pp. 4682-4690

45 I. Rayment, W.R. Rypniewski, K. SchmidtBäse, R. Smith, D.R. Tomchick, M.M. Benning, D.A. Winkelmann, G. Wesenberg, H.M. Holden. Threedimensional structure of myosin subfragment-1: A molecular motor. Science, 261 (1993), pp. 50-58

46 A.S. Rovner, Y. Freyzon, K.M. Trybus. An insert in the motor domain determines the functional properties of expressed smooth muscle myosin isoforms. J Muscle Res Cell Motil, 18 (1997), pp. 103-110

47 S.D. Russell, N. Cambron, B. Nadal-Ginard, R.G. Whalen. Thyroid hormone induces a nerve-independent precocious expression of fast myosin heavy chain mRNA in rat hindlimb skeletal muscle. J Biol Chem, 263 (1988), pp. 6370-6374

48 M. Sata, W.F. Stafford, K. Mabuchi, M. Ikebe. The motor domain and the regulatory domain of myosin solely dictate enzymatic activity and phosphorylation-dependent regulation, respectively. Proc Natl Acad Sci USA, 94 (1997), pp. 91-96 
49 S. Schiaffino, L. Saggin, A. Viel, S. Ausoni, S. Sartore, L. Gorza. Muscle fiber types identified by monoclonal antibodies to myosin heavy chains. G. Genzi, L. Packer, N. Siliprandi (Eds.), Biochemical Aspects of Physical Exercise, Elsevier, Amsterdam (1986), pp. 27-34

50 S. Schiaffino, L. Gorza, S. Sartore, L. Saggin, S. Ausoni, M. Vianello, K. Gundersen, T. Lomo. Three myosin heavy chain isoforms in type 2 skeletal muscle fibres. J Muscle Res Cell Motil, 10 (1989), pp. 197-205

$51 \mathrm{~S}$. Schiaffino, C. Reggiani. Molecular diversity of myofibrillar proteins: Gene regulation and functional significance. Physiol Rev, 76 (1996), pp. 371-423

52 S. Schiaffino, C. Reggiani. Myosin isoforms in mammalian skeletal muscle. J Appl Physiol, 77 (1994), pp. 493501

53 JR Sellers, et al. Myosin-specific adaptations of the motility assay. IM Scholey (Ed.), Methods in Cell Biology, 39, Academic Press, New York (1993), pp. 23-49

54 J.R. Sellers, H.V. Goodson, F. Wang. A myosin family reunion. J Muscle Res Cell Motil, 17 (1996), pp. 7-22

55 J.V. Small, D.U. Furst, J. De May. Localization of filamen in smooth muscle. J Cell Biol, 102 (1986), pp. 210220

56 V. Smerdu, I. Karsch-Mizrachi, M. Campione, L. Leinwand, S. Schiaffino. Type Ilx myosin heavy chain transcripts are expressed in type Illb fibers of human skeletal muscle. Am J Physiol (Cell Physiol), 267 (36) (1994), pp. 1723-1728

57 K. Sobue, J.R. Sellers. Caldesmon, a novel regulatory protein in smooth muscle and nonmuscle actomyosin systems. J Biol Chem, 266 (1991), pp. 12115-12118

58 A.P. Somlyo. Myosin isoforms in smooth muscle: How may they affect function and structure? J Muscle Res Cell Motil, 14 (1993), pp. 557-563

59 A.P. Somlyo, A.V. Somlyo. Signal transduction and regulation in smooth muscle. Nature, 372 (1994), pp. 231236

60 M.P. Sparrow, M.A. Mohammad, A. Arner, P. Hellstrand, J.C. Rüegg. Myosin composition and functional properties of smooth muscle from the uterus of pregnant and non-pregnant rats. Pflüg Arch, 412 (1988), pp. 624-633

61 F.A. Sreter, A.R. Luff, J. Gergely. Effect of cross reinnervation on physiological parameters and on properties of myosin and sarcoplasmic reticulum of fast and slow muscles of the rabbit. J Gen Physiol, 66 (1975), pp. 811-821

62 H.L. Sweeney, B.F. Bowman, J.T. Stull. Myosin light chain phosphorylation in vertebrate striated muscle: Regulation and function. Am J Physiol (Cell Physiol), 264 (33) (1993), pp. 1085-1095

63 H.L. Sweeney, M.J. Kushmerick, K. Mabuchi, F.A. Sreter, J. Gergely. Myosin alkali light chain and heavy chain variations correlate with altered shortening velocity of isolated skeletal muscle fibers. J Biol Chem, 263 (1988), pp. 9034-9039

64 B. Swynghedauw. Developmental and functional adaptation of contractile proteins in cardiac and skeletal muscles. Physiol Rev, 66 (1986), pp. 710-771

65 M.P. Walsh. Calmoduline and the regulation of smooth muscle contraction. Mol Cell Biochem, 135 (1994), pp. 21-41

66 M.P. Walsh. Regulation of vascular smooth muscle tone. Can J Physiol Pharmacol, 72 (1994), pp. 919-936

67 M.P. Walsh, G.J. Kargacin, J. Kendrick-Jones, T.M. Lincoln. Intracellular mechanisms involved in the regulation of vascular smooth muscle tone. Can J Physiol Pharmacol, 73 (1995), pp. 565-573

68 D.M. Warshaw, W.J. McBride, S.S. Work. Corkscrew-like shortening in single smooth muscle cells. Science, 236 (1987), pp. 1457-1459

69 J.J. Widrick, S.W. Trappe, C.A. Blaser, D.L. Costill, R.H. Fitts. Isometric force and maximal shortening velocity of single muscle fibers from elite master runners. Am J Physiol (Cell Physiol), 271 (40) (1996), pp. C666C675 
70 C.J. Wingard, A.K. Browne, R.A. Murphy. Dependence of force on length at constant cross-bridge phosphorylation in the swine carotid media. J Physiol, 488 (1995), pp. 729-739

71 J-Q. Xu, B.A. Harder, P. Uman, R. Craig. Myosin filament structure in vertebrate smooth muscle. J Cell Biol, 134 (1996), pp. 53-66

72 A.M.C. Zanellato, A.C. Borrione, L. Giuriato, M. Tonello, G. Scannapieco, P. Pauletto, S. Sartore. Myosin isoforms and cell heterogeneity in vascular smooth muscle. I. Developing and adult bovine aorta. Dev Biol, 141 (1990), pp. 431-446

73 A.M.C. Zanellato, A.C. Borrione, M. Tonello, G. Scannapieco, P. Pauletto, S. Sartore. Myosin isoform expression and smooth muscle cell heterogeneity in normal and atherosclerotic rabbit aorta. Arteriosclerosis, 10 (1990), pp. 996-1009

${ }^{1}$ Presented inpart at the 1996 American Thoracic Society Assembly on Respiratory Structure and Function Symposium 'Myosin Structure and Function in Smooth and Skeletal Muscle'. 